\title{
A repeated short educational intervention improves asthma control and quality of life
}

\author{
Vicente Plaza ${ }^{1}$, Meritxell Peiró ${ }^{1}$, Montserrat Torrejón ${ }^{1}$, Monica Fletcher², \\ Antolín López-Viña ${ }^{3}$, José María Ignacio ${ }^{4}$, José Antonio Quintano ${ }^{5}$, \\ Santiago Bardagi $i^{6}$ and Ignasi Gich ${ }^{7}$ on behalf of the PROMETHEUS Study Group ${ }^{8}$
}

\begin{abstract}
Affiliations: 'Dept of Respiratory Medicine, Hospital de la Santa Creu i Sant Pau, Institut d'Investigació Biomèdica Sant Pau (IIB Sant Pau), Universitat Autónoma de Barcelona, Barcelona, Spain. ${ }^{2}$ Education for Health, Warwick, UK. ${ }^{3}$ Pulmonology Dept, Hospital Universitario Puerta de Hierro Majadahonda, Madrid, Spain. ${ }^{4}$ Hospital Serranía de Ronda, Ronda, Málaga, Spain. ${ }^{5}$ Centro de Salud Lucena I, Lucena, Córdoba, Spain. ${ }^{6}$ Pulmonology Dept, Hospital de Mataró, Mataró, Barcelona, Spain. ${ }^{7}$ Dept of Epidemiology, Hospital de la Santa Creu i Sant Pau, Institut d'Investigació Biomèdica Sant Pau (IIB Sant Pau), Universitat Autónoma de Barcelona, Barcelona, Spain. ${ }^{8} \mathrm{~A}$ full list of the PROMETHEUS Study Group investigators and participating centres can be found in the Acknowledgements section.
\end{abstract}

Correspondence: Vicente Plaza, Servei de Pneumologia, Hospital de la Santa Creu i Sant Pau, C/Sant Antoni M. Claret 167, 08025 Barcelona, Spain. E-mail: vplazadsantpau.cat

ABSTRACT We assessed the effectiveness of an asthma educational programme based on a repeated short intervention (AEP-RSI) to improve asthma control (symptom control and future risk) and quality of life.

A total of 230 adults with mild-to-moderate persistent uncontrolled asthma participated in a 1-year cluster randomised controlled multicentre study. The AEP-RSI was given in four face-to-face sessions at 3-month intervals, and included administration of a written personalised action plan and training on inhaler technique. Centres were randomised to the AEP-RSI (intervention) group or usual clinical practice group. Specialised centres using a standard educational programme were the gold standard group.

A significant improvement in the Asthma Control Test score was observed in all three groups $(\mathrm{p}<0.001)$, but improvements were higher in the intervention and gold standard groups than in the usual clinical practice group ( $\mathrm{p}=0.042$ ), which also showed fewer exacerbations (mean \pm SD; $1.20 \pm 2.02$ and $0.56 \pm 1.5$ versus 2.04 \pm 2.72 , respectively) and greater increases in the Mini Asthma Quality of Life Questionnaire scores $(0.95 \pm 1.04$ and $0.89 \pm 0.84$ versus $0.52 \pm 0.97$, respectively).

The AEP-RSI was effective in improving asthma symptom control, future risk and quality of life.

@ERSpublications

An educational programme based on a repeated short intervention for asthma is effective and easily to use in practice http://ow.ly/QUEx7

Editorial comment in: Eur Respir J 2015; 46: 1262-1264 [DOI: 10.1183/13993003.01303-2015].

Received: March 212015 | Accepted after revision: July 092015 | First published online: Sept 242015

Clinical trial: This study is registered at www.clinicaltrials.gov with identifier number NCT01282359.

Support statement: This study was funded by the Integrated Research Asthma Programme (PII Asthma) of the Spanish Respiratory Society (SEPAR). Unconditional funding was provided by Chiesi, who did not participate in data collection, interpretation of the results or writing of the manuscript.

Conflict of interest: Disclosures can be found alongside the online version of this article at erj.ersjournals.com.

Copyright OERS 2015 


\section{Introduction}

Education and guidance on asthma self-management have become increasingly important in recognition of the need to improve asthma management, reduce morbidity and lower costs of care. Structured individualised self-management education programmes that include written action plans for adjusting treatment based on the degree of asthma control are effective, and lead to a reduction in the risk of exacerbations and indirect costs, and an improvement in quality of life [1-3]. Unfortunately, the reality is that there are few healthcare centres and professionals that offer education programmes to their patients with asthma [4]. It has been argued that complexity and high cost are barriers to implementing self-management educational programmes in clinical practice.

Research related to asthma education has examined the simplified approaches of the current programmes intended to focus the content on essential aspects. However, use of limited asthma education (i.e. information only) does not appear to improve health outcomes in adults with asthma [2]. Various types of short-format and short-term educational interventions in asthma patients have been developed [5-8]. However, these programmes have provided inconsistent results due to differences in terms of design, components of patient education, setting in which the disease is addressed or outcomes considered. Therefore, new evidence from robustly designed studies performed in large samples of patients with asthma and assessing the beneficial effects of a real short-term education programme (rather than instructional interventions only) on asthma symptoms and future morbidity is needed. The aim of this study was to assess the effectiveness of an asthma educational programme based on a repeated short intervention (AEP-RSI) to improve symptoms and quality of life as well as to prevent future asthma exacerbations in adult patients with asthma.

\section{Methods}

\section{Study design and participants}

Between June 2011 and February 2013, a cluster randomised controlled multicentre study was performed in adult patients with asthma. The objective of the study was to assess the effectiveness of the AEP-RSI to improve asthma symptoms and to prevent asthma exacerbations (future risk), and, consequently, to improve health-related quality of life. The duration of the study was 12 months and all patients included were visited by their physician four times (one visit in every 3 months), when their asthma treatment was adjusted.

A total of 25 centres throughout Spain (15 pulmonology services, one allergy service and nine primary care centres) agreed to participate in the study. Five pulmonology services with recognised excellence in asthma care already administered education interventions to their patients with asthma following the recommended programmes [9-11]. These were centres with technical resources and professionals specialised in educational programmes in their teams, which have also been recognised as centres with Specialised Asthma Units, the maximum level provided by the Spanish Respiratory Society (SEPAR) in the clinical excellence programme of this society (accreditation programme for asthma units). These centres were not randomised and were included in the "gold standard" group. The remaining 20 centres were randomised to the "intervention" group (administration of the AEP-RSI programme) ( $\mathrm{n}=10)$ or medical care without such education, the "usual clinical practice" group $(\mathrm{n}=10)$.

Patients were consecutively enrolled from the outpatient clinics of the pulmonology and primary care centres involved in the study. Eligibility included men and women aged between 18 and 70 years, with mild-to-moderate persistent uncontrolled asthma. The diagnosis of asthma was accepted when a patient with common clinical symptoms of the disease and airflow limitation had a positive bronchodilator test $(\geqslant 12 \%$ change in forced expiratory volume in $1 \mathrm{~s}$ ) or a daily peak expiratory flow variability $>20 \%$ or a positive methacholine challenge test documented in the medical record. Severity of asthma before treatment adjustment was defined according to the Global Initiative for Asthma criteria [12] and uncontrolled asthma was define as a score $<20$ in the Asthma Control Test (ACT) [13]. Patients with severe comorbidities or those who had an asthma exacerbation episode that required treatment with oral corticosteroids within 30 days before enrolment were excluded from the study.

The study was conducted in accordance with the Declaration of Helsinki principles (18th World Medical Assembly), and was approved by the Clinical Research Ethics Committee of Hospital de la Santa Creu i Sant Pau (approval number 72/2010) and registered at http://www.clinicaltrials.gov (NCT02282359). Written informed consent was obtained from all participants. Personal identification data were anonymised.

\section{AEP-RSI of the intervention group}

Asthma patients enrolled in the intervention centres received the education programme, which was taught on-site by the educator, physician and/or registered nurse. The intervention was implemented in a series of four consecutive visits, which were scheduled every 3 months. The education programme included the following three components: 1) provision of basic information on asthma, 2) provision of a short 
personalised asthma action plan, and 3) training to use the inhalers devices correctly and revision of the inhaler technique. The three components of the education programme were checked at each study visit.

In relation to general information on asthma, a printed copy of the Spanish Asthma Guidelines (GEMA) for Patients [14] was given to each participant at the first visit. Also, at each of the three subsequent visits, the asthma educator briefly explained five simple recommendations and emphasised the importance to follow these recommendations (table 1). Supplementary oral information on allergen avoidance measures was also given to those patients who were sensitised.

A short written personalised asthma action plan was established by the physician for each individual patient according to the patient's symptoms. The mini action plan was based in part on the GEMA recommendations [15] and adapted to essential aspects (table 1). Briefly, as step 1, patients were instructed to triple the dose of inhaled steroids that they were usually receiving and to start reliever medication if they had not done before (inhaled salbutamol, two puffs every 6 or $8 \mathrm{~h}$ ) for 3-5 days. If not improved (step 2), a short course of oral steroids (prednisone $30 \mathrm{mg}$ ) for 5-10 days was indicated (table 1). Comprehension of the mini action plan was checked at each visit. Patients were trained in correct inhaler technique using placebo inhaler devices. At each visit, the patient's inhaler technique was checked and technique errors were corrected. Therefore, the AEP-RSI met criteria for an educational intervention, including a teaching method based on a personalised approached tailored to the patient's characteristics, face-to-face reinforcement actions and placebo inhaler devices to check adequacy of the inhaler technique.

To assess the feasibility and time taken to administer the AEP-RSI, a pilot study with five patients was performed. The time $($ mean \pm SD) for implementation of the educational programme at the first visit was $10.7 \pm 3.8 \mathrm{~min}$ and for each of the follow-up visits was $6.4 \pm 2.3 \mathrm{~min}$.

In order to standardised the educational messages received by the patients of the AEP-RSI group, their physicians and/or nurses were first trained in an accredited on-line course (http://www.gemasma.com) based on the GEMA recommendations for educators [16], and then attended a 1-day on-site course in which the AEP-RSI was fully explained, and materials and placebo inhalers were provided.

\section{Asthma education programmes in the gold standard group}

Centres of this group administered education interventions following the usual recommended programmes [9-11]. Briefly, the education programme was implemented by a nurse (trained in communication skills and changing behaviour techniques) to each individual patient coinciding with scheduled medical visits. In the first visit, the programme was fully explained, the patient's concerns, beliefs and expectations were investigated, and a therapeutic goal to which the patient agreed was established. Information was provided on basic asthma concepts (chronic disease, need to take medication uninterruptedly, difference between inflammation and bronchoconstriction, and symptoms) taking into account the clinical characteristics,

TABLE 1 Components of the asthma educational programme based on a repeated short intervention implemented in the intervention group at each study visit

Five simple asthma-related recommendations

1. Better to prevent asthma exacerbation. Do not forget to take your medication daily and at the doses prescribed.

2. Do not smoke and do not allow other people to smoke in your presence.

3. If you lose control of asthma, ACT!, use the action plan provided to you, but get medical help.

4. Do not take aspirin or its derivatives.

5. In case you suffer from allergy (mite, pets, pollens, etc.) avoid exposure.

\section{Mini action plan}

Patient's name:

Date:
If in the last $24 \mathrm{~h}$ your asthma has worsened due to the presence of

- Shortness of breath or wheezing more than two times, or

- Shortness of breath or wheezing in the last night, or

- Need to use your quick-relief bronchodilator more than three times.

Increase treatment as follows:

1. Increase ......................... and maintain during ...... days.

2. If not improve, start ..................... (prednisone) $\mathbf{3 0} \mathbf{~ m g , ~}$ 1 pill a day, and maintain during ...... days (maximum 10 days).

3. Ask for an appointment with your doctor. 
concerns and agreed objective for each patient. Placebo inhalers were used to teach the inhaler technique. In the second visit, adherence to treatment was commented on and the importance of compliance was emphasised; medication was also adjusted to the patient's daily routine activities. Patients were taught about environmental measures, and a written action plan based on symptoms and peak flow measurement at home was provided. Patients were instructed on how to use the peak flow metre device. Patient's knowledge and skills regarding the correct use of inhalers, environmental measures, monitoring of symptoms and written action plan were reinforced at each follow-up visit. Emphasis was placed on the importance of being adherent to the prescribed medication and, in some cases, techniques to prevent forgetfulness were used.

\section{Study procedures}

At the first visit (visit 1), patients in the three study groups signed an informed consent, and completed general questions about sociodemographic variables, education level, asthma clinical characteristics and treatment. Patients also completed a Spanish validated version of the ACT [13, 17]. Comorbid conditions were assessed with the Charlson Comorbidity Index [18] and health-related quality of life was assessed with the Mini Asthma Quality of Life Questionnaire (MiniAQLQ) [19, 20]. Spirometry was performed according to European Respiratory Society/American Thoracic Society guidelines [21], using the predicted values for a Mediterranean population [22].

\section{Study variables}

The primary variable was the control of asthma symptoms assessed by the ACT scores during the study period (visits 1-4). Secondary variables were age, gender, body mass index (BMI), education level (no studies/ primary education, secondary education/university studies), smoking status (current smoker, never-smoker, ex-smoker) and Charlson Comorbidity Index score at visit 1; MiniAQLQ scores and spirometric data at visits 1 and 4; and requirement of short and long oral steroids cycles, hospitalisations, emergency room visits, unscheduled medical visits, asthma exacerbations (defined as a composite variable that included the number of unscheduled medical visits, emergency room visits and hospitalisations), and treatment at all study visits.

\section{Sample size calculation and statistical analysis}

The sample size was calculated to detect a statistically significant difference of 4 points in the ACT score (double the minimal clinically relevant value of this test) assuming a mean ACT score of 18 in one of the study groups, with a $50 \%$ variability and standard deviation of 9 . Thus, accepting $20 \%$ of patients lost to follow-up, 200 patients were required to answer the study question (beneficial effects of the AEP-RSI intervention). A significance level of $5 \%$ was accepted. The size was somewhat inflated to compensate for a possible intracluster correlation. The minimal power was $80 \%$.

Categorical variables are expressed as absolute and relative frequencies and quantitative variables as mean \pm SD. Groups were compared using analysis of variance (ANOVA), Chi-squared test and post hoc Tukey's honestly significant difference procedure when appropriate. An intention-to-treat analysis using last observation carried forward was used for the analysis of the primary variable in the entire population. Analysis of the primary variable also included two-way repeated measures ANOVA, in which factors were time (ACT scores, four levels) and intervention (three levels). Additionally, to correct for the centre's randomisation (cluster analysis study), the ANOVA was performed by adding the centre factor (defined as random), using a mixed procedure, and the a covariance matrix was chosen using the Akaike information criterion [23]; this analysis was also carried out adding confounding variables such as education level, BMI and MiniAQLQ score. Statistical analysis was performed with SPSS version 21.0 (IBM-SPSS, Inc., Chicago, IL, USA). Statistical significance was set at $\mathrm{p}<0.05$.

\section{Results}

After randomisation, one centre from the intervention group and two centres from the usual clinical practice group refused to take part in the study. In one case, the management of the centre finally did not grant permission and the remaining two centres claimed work overload. Therefore, a total of 22 centres with 250 patients were included in the study. However, 10 patients (six in the intervention group and four in the usual clinical practice group) did not complete the follow-up visits, and 10 other patients (one in the intervention group and nine in the usual clinical practice group) did not meet the inclusion criteria and were excluded from the analysis. Data from 230 patients (intervention group, $\mathrm{n}=114$; usual clinical practice group, $n=71$; gold standard group, $n=45$ ) were analysed. The flowchart of the study population is shown in figure 1 .

As shown in table 2, most patients were women, age $46.1 \pm 13.7$ years and moderate persistent asthma. Statistically significant differences among patients in the three study groups were not found, except for a lower percentage of patients with mild asthma and a higher percentage of patients with moderate asthma 


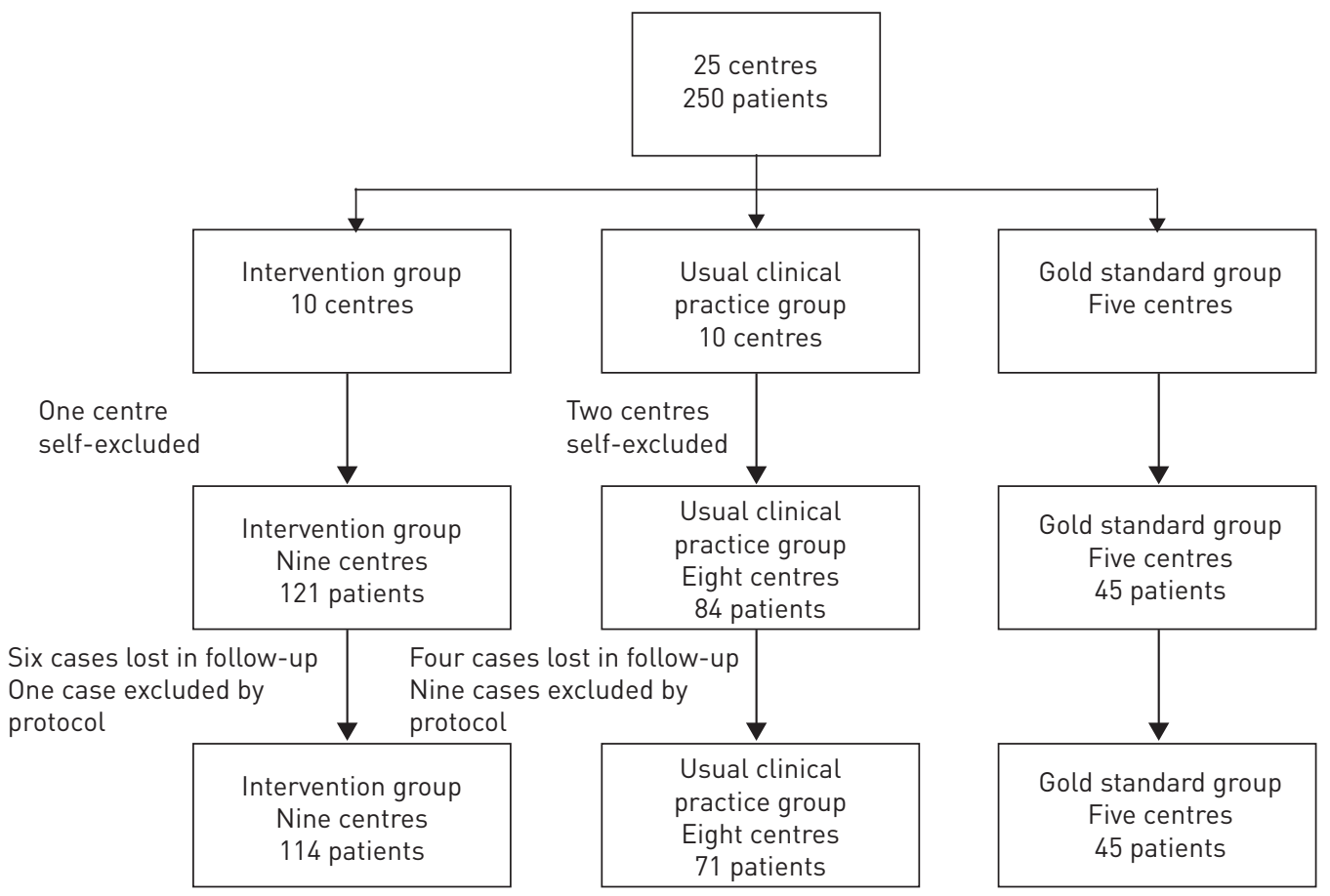

FIGURE 1 Flowchart of the centres and patients included in the study.

in the intervention group as compared with patients in the usual clinical practice group, which resulted in a significantly lower ACT score in the usual clinical practice group than in the intervention group.

\section{ACT score}

In relation to control of asthma symptoms, the mean ACT score improved significantly over the 12-month follow-up period in the three groups, with significant differences $(p<0.001)$ already from the second visit. Progressive improvement in ACT score showed a tendency to flatten at visits 3 and 4 (figure 2); however, at the end of the study, the mean ACT scores were $21.18 \pm 0.38$ and $20.42 \pm 0.60$ in the gold standard and intervention groups, respectively, as compared with $19.56 \pm 0.45$ in the usual clinical practice group $(p=0.042)$. Significant differences between groups were also found in the mixed ANOVA model $(\mathrm{p}=0.039)$.

\section{Prevention of future asthma-related events}

As shown in table 3, patients in the intervention and the gold standard groups suffered from fewer asthma exacerbations as compared with the usual clinical practice group $(p=0.003)$, which resulted in a lower number of unscheduled medical visits $(\mathrm{p}=0.001)$. Differences in the number of patients requiring inpatient care or differences in spirometric values were not observed. The mean number of both short and long courses of oral steroids was also similar in the three study groups, although there was a trend for a higher use of oral steroids (both short and long courses) in the usual clinical practice group as compared with the intervention and gold standard groups (table 3).

\section{Health-related quality of life}

According to the minimal clinical difference for the MiniAQLQ established as 0.5 points [24], patients in the three groups improved their MiniAQLQ scores at the end of the study as compared with baseline: the intervention group increased $0.95 \pm 1.04$, the gold standard group increased $0.89 \pm 0.84$ and the usual clinical practice group increased $0.52 \pm 0.97$ points. However, the increases observed in the intervention and gold standard groups were significantly $(\mathrm{p}=0.019)$ higher compared with the increase of the usual clinical practice group.

\section{Discussion}

Although self-management education programmes are recommended by clinical practice guidelines [12, $15,25]$ and expert panels [26] with a high level of evidence, implementation at the clinical level is still limited [4, 27], which contributes to suboptimal asthma control [28, 29]. This study shows that a short-format repeated educational intervention (AEP-RSI) delivered by trained physicians and/or nurses 
TABLE 2 Sociodemographic, asthma morbidity, clinical characteristics and spirometric values observed at visit 1 in all patients and distributed in the three study groups

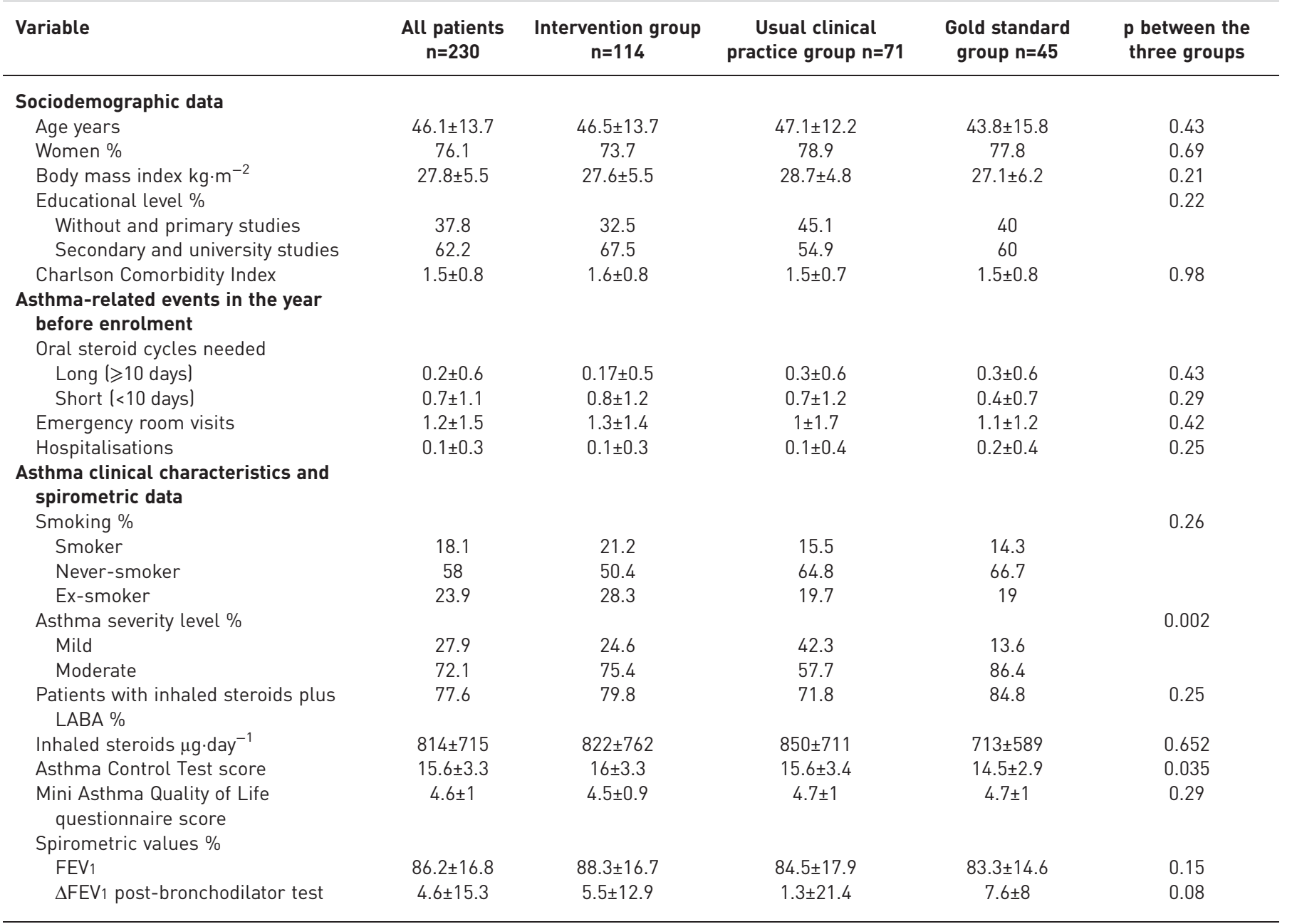

Data are presented as mean $\pm \mathrm{SD}$, unless otherwise stated. FEV1: forced expiratory volume in $1 \mathrm{~s}$; LABA: long-acting $\beta$-agonists.

was more effective to achieve good control of asthma symptoms, to improve quality of life, and to reduce exacerbations and unscheduled medical visits during the 12-month follow-up period compared with usual clinical practice. In terms of other outcomes, including emergency room visits, hospital admissions and oral steroid cycles (long and short courses), data obtained in the intervention group were somewhat worse than data obtained in the gold standard group, but better than those found in the usual care group.

FIGURE 2 Mean scores of the Asthma Control Test (ACT) at each of the study visits. \#: significant differences as compared with baseline; ๆ: improvements during the 1-year follow-up period were greater in the intervention and gold standard groups than in the usual clinical practice group.

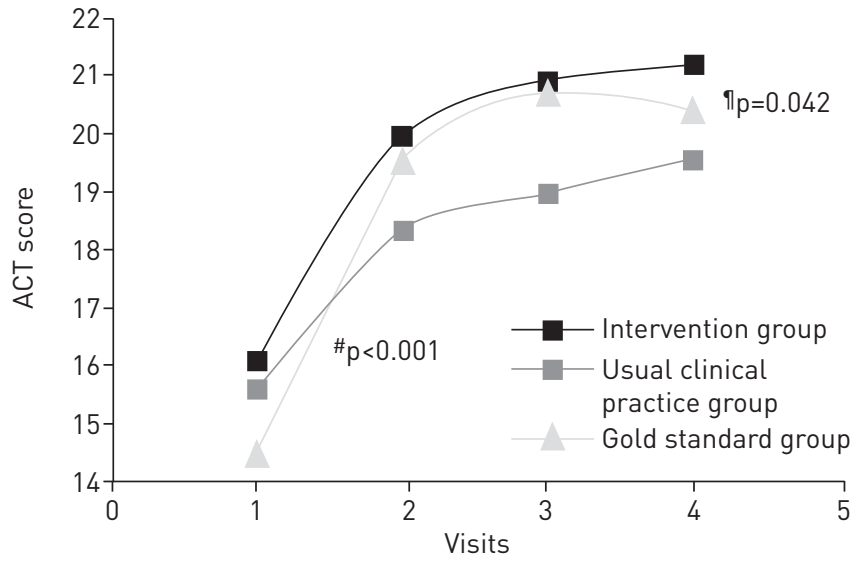


TABLE 3 Impact of the asthma educational programme based on a repeated short intervention on the future risk variables analysed and changes in the asthma treatment at the end of the follow-up as compared with baseline

\begin{tabular}{|c|c|c|c|c|}
\hline Variable & $\begin{array}{l}\text { Intervention } \\
\text { group } n=114\end{array}$ & $\begin{array}{l}\text { Usual clinical } \\
\text { practice group } n=71\end{array}$ & $\begin{array}{l}\text { Gold standard } \\
\text { group } n=45\end{array}$ & $\begin{array}{l}\mathrm{p} \text { between } \\
\text { groups }\end{array}$ \\
\hline \multicolumn{5}{|l|}{ Asthma-related events at follow-up } \\
\hline Unscheduled medical visits & $0.8 \pm 1.41$ & $1.34 \pm 1.65$ & $0.28 \pm 0.68$ & $0.001^{\#}$ \\
\hline Emergency room visits & $0.41 \pm 1.12$ & $0.69 \pm 1.50$ & $0.25 \pm 0.88$ & 0.160 \\
\hline Hospital admission & $0.0 \pm 0.0$ & $0.15 \pm 0.12$ & $0.26 \pm 0.16$ & 0.350 \\
\hline \multicolumn{5}{|l|}{ Oral steroid cycles needed } \\
\hline Short course $(<10$ days $)$ & $0.34 \pm 0.89$ & $0.44 \pm 0.85$ & $0.23 \pm 0.54$ & 0.430 \\
\hline \multicolumn{5}{|l|}{ Spirometric changes versus baseline } \\
\hline $\mathrm{FEV}_{1} \%$ & $1.89 \pm 13.52$ & $0.19 \pm 10.72$ & $4.16 \pm 15.34$ & 0.340 \\
\hline$\Delta \mathrm{FEV}_{1}$ post-bronchodilator test $\%$ & $1.63 \pm 17.33$ & $3.61 \pm 18.74$ & $-1.86 \pm 16.02$ & 0.343 \\
\hline \multicolumn{5}{|l|}{$\begin{array}{l}\text { Asthma treatment changes } \\
\text { versus baseline }\end{array}$} \\
\hline
\end{tabular}

The present findings support the benefits of simple and short-format educational programmes. Of note, the mini action plan included three simple premises to easily identify loss of asthma control and three simple progressive therapeutic measures (including the use of oral corticosteroids) to act accordingly. This brief written mini action plan is very easy and quick to explain by healthcare professionals as well as easily understood and followed by patients, overcoming one of the barriers to implementation of action plans, which many patients sometimes perceive as difficult to understand and apply. Although all three study groups showed a significant increase in ACT and MiniAQLQ scores, well-controlled asthma (ACT score >20) was only observed in the asthma education programme groups, either the AEP-RSI intervention group or the gold standard group. Patients in the usual clinical practice group showed less severe asthma at baseline, with a higher percentage of patients with mild asthma as compared with the intervention and gold standard groups; However, asthma-related events at follow-up, including exacerbations and unscheduled medical visits, were significantly worse in the usual clinical practice group than those observed in the other two groups. Moreover, although those in the intervention and gold standard groups were able to self-administer short courses of oral corticosteroids if they became uncontrolled in accordance with their asthma action plans, patients in the usual clinical practice group used oral steroids with the same frequency (even with a non-significant increased use) and showed a higher rate of exacerbations.

Recently, the UK Review of Asthma Deaths, a confidential enquiry that investigated 900 asthma deaths in 2012, showed several deficiencies in patient care and concluded that the majority of asthma deaths could have been prevented [30]. One of the areas of deficit identified was related to the limited use of asthma educational programmes, in particular using personal asthma action plans (less than a quarter of patients who died had one). In contrast, in the Finnish asthma programme launched in 1994, which resulted in a decrease in asthma mortality amongst other outcomes, success was based on four principles, one of which was to educate patients using a written management plan as the preferred method [31].

Therefore, it has been argued that one of the keys to reduce deaths from asthma may be improving knowledge and skills, leading to a transfer of knowledge to the patient, a form of patient empowerment [32]. In this context, an AEP-RSI may be an easy-to-use tool to achieve the patient implication and could provide some of the answers to the research needs (pragmatic approaches, implement asthma self-management) recently identified by the International Primary Care Respiratory Group [33].

Our results are not in agreement with data reported in other studies reporting partial improvements with the use short-format educational programmes. In the study by DALCIN et al. [5] in 115 asthma patients who participated in one individualised session and who were evaluated after 3 months, a significant decrease of patients visiting emergency services was noted, but the level of asthma control did not improve significantly. In the study by Morell et al. [7], 334 asthma patients underwent a 5-min educational intervention, which was repeated at 3 months, with a final assessment at 6 months. As compared with control patients, a reduction in the number of exacerbations was observed without significant changes in the control of asthma 
(according to the asthma control questionnaire). In the study by MANCUSO et al. [6] of 197 patients who attended the emergency department because of respiratory symptoms, a self-management education intervention delivered in the emergency department and reinforced by telephone did not provide any incremental benefit for quality of life and short-term repeated emergency department visit outcomes. In the study by Côté et al. [8], 98 patients consulting urgently for an acute asthma exacerbation were assigned to usual treatment, limited education (teaching of the inhaler technique plus self-action plan given by the on-call physician) or the same limited education plus a structured educational programme emphasising self-management. After 12 months, only patients in the structured educational programme showed a significant reduction in the number of urgent visits for an acute exacerbation of asthma and a significant improvement in the quality of life scores.

Regardless of differences in methodology used in these aforementioned studies, which may account for the disparity in the results, better outcomes observed in the present study could be explained primarily by two reasons. First, the AEP-RSI intervention implemented in our study, although brief, met criteria for an educational intervention itself as compared with short-format interventions assessed in other studies [5-8] in which more instructional-type interventions were used. A therapeutic educational programme should include a teaching method as it is well-known that behaviour remains unmodified when information only or minimal instructions are provided [1, 2]. For this reason, a personalised approach to the disease of each patient is recommended, which should be tailored to the patient's social, cultural and environmental characteristics [34]. Moreover, it has been shown that adult asthma patients have identifiable preferences for active levels of participation in treatment decision making and that communication is an area requiring improvement [35]. Second, the short educational intervention in the AEP-RSI programme included face-to-face reinforcement actions during subsequent clinical visits, including supervision of the inhaler technique using placebo inhaler devices, unlike other studies in which actions included a single or two initial visits [5-8], or only telephone reinforcement [6]. It has been established that regular educational opportunities associated with frequent visits by the patient improves the outcomes of educational programmes, benefits patient-physician relationships and results in greater patient engagement in self-management [1,36-38]. Finally, it is important to note that patient improvement is part of a structured educational programme, although educational programmes need to be seen in the context of a structured asthma review, such as that proposed in the SIMPLES (smoking status, inhaler technique, monitoring, pharmacotherapy, lifestyle, education and support) primary care approach for adults with difficult asthma [39].

The cluster randomised controlled design of the study and the set of variables analysed are strengths of the present findings. The ACT score differences between groups at baseline do not limit the results observed, because during the subsequent 1-year follow-up period, significant differences in the changes in the ACT score improvements between groups were observed. It is possible that improvements obtained in the usual practice group may be explained by a Hawthorne effect, but the magnitude of improvements after 12 months was significantly lower than that observed in the AEP-RSI intervention and gold standard groups. Therefore, the potential influence of the Hawthorne effect does not affect the interval validity of the study.

In conclusion, an AEP-RSI provided a significant improvement in asthma control, symptoms and future risk, and health-related quality of life as compared with usual clinical practice. Cost benefits are likely to be associated with the implementation of the programme, but this aspect was not assessed in the present study. Even though short educational interventions should not replace standard and complete self-management educational programmes, the implementation of an AEP-RSI is a pragmatic option to improve the management of asthma patients in centres with limited resources that are lacking standardised asthma educational programmes.

\section{Acknowledgements}

The authors are grateful to all study participants. We also thank Marta Pulido for editing the manuscript and editorial assistance. The fees for medical editing were supported by Chiesi Spain.

PROMETHEUS (PROgraMme based on a short intErvention To improve tHE asthma control (symptom control and fUture riSk)) Study Group investigators and participating centres in alphabetical order: C. Almonacid Sánchez (Hospital General de Guadalajara, Guadalajara); M.T. Bazús Gónzález (Hospital General de Oviedo, Instituto Nacional de Silicosis, Oviedo); R. Camporro Martín (Hospital General de Oviedo, Instituto Nacional de Silicosis, Oviedo); D. Capdevila Folguera (Centro de Atención Primaria Maragall/EAP Congrés, Institut Català de la Salut, Barcelona); T. Caruana Careaga (Hospital Clínica Puerta de Hierro Majadahonda, Madrid); M.J. Cons González (Hospital de Manacor, Mallorca); J. Contreras Porta (Hospital Universitario La Paz, Madrid); M.J. del Estal López (Hospital Infanta Sofía, Madrid); F.A. Freixas Laporta (Centro Atención Primaria Dreta Eixample, Institut Català de la Salut, Barcelona); J.L. García Rivero (Hospital Comarcal de Laredo, Laredo, Cantabria); L. Ginel Mendoza (Centro de Salud Ciudad Jardín, Málaga); A. García Solana (Centro de Atención Primaria Dreta Eixample, Institut Català de la Salut, Barcelona); J.L. Gómez Jiménez (Centro de Salud Menasalbas, Toledo); M.C. Gómez Neira (Hospital Lucua Augusti, Lugo); F. Gómez Ruiz (Centro Salud de Bargas, Toledo); M.V. González Gutiérrez (Hospital de Mataró, Mataró, Barcelona); J.A. Gullón Blanco (Hospital San Agustín, Avilés, Asturias); C. Josep Candelich (Hospital de Mataró, Mataró, Barcelona);

J. Hernández Úrculo (Centro Salud La Vega-Zapatón, Torrelavega, Cantabria); I. Lassaletta Goñi (Hospital Universitario 
de Alicante, Alicante); M.C. López Neira (Hospital Lucua Augusti, Lugo); M.I. López Serrano (Hospital Infanta Sofía, Madrid); E. Martínez Moragón (Hospital de Sagunto, Sagunto, Valencia); L. Pérez de Llano (Hospital Lucua Augusti, Lugo); C.M. Quintano Reina (Centro de Salud Lucena I, Lucena, Córdoba); C. Rodríguez García (Hospital San Agustín, Avilés, Asturias); J. Serra Batlles (Hospital General de Vic, Vic, Barcelona); M. Torrejón Lázaro (Hospital de la Santa Creu i Sant Pau, Barcelona); J.A. Trigueros Carrero (Centro de Salud Menasalbas, Toledo) (Spain).

\section{References}

1 Gibson PG, Powell H, Coughlan J, et al. Self-management education and regular practitioner review for adults with asthma. Cochrane Database Syst Rev 2003; 1: CD001117.

2 Gibson PG, Powell H, Coughlan J, et al. Limited (information only) patient education programs for adults with asthma. Cochrane Database Syst Rev 2002; 2: CD001005.

3 Wolf FM, Guevara JP, Grum CM, et al. Educational interventions for asthma in children. Cochrane database Syst Rev 2003; 1: CD000326.

4 Plaza V, Bolivar I, Giner J, et al. Knowledge of and attitudes and adherence to the Spanish Guidelines for Asthma Management (GEMA) among Spanish health care professionals: the GEMA test Project. Arch Bronconeumol 2008; 44: $245-251$.

5 Dalcin Pde TR, Grutcki DM, Laporte PP, et al. Impact of a short-term educational intervention on adherence to asthma treatment and on asthma control. J Bras Pneumol 2011; 37: 19-27.

6 Mancuso CA, Peterson MGE, Gaeta TJ, et al. A randomized controlled trial of self-management education for asthma patients in the emergency department. Ann Emerg Med 2011; 57: 603-612.

7 Morell F, Ojanguren I, Cordovilla R, et al. Two short interventions to reduce health care requirements in asthma patients. A multicentre controlled study (ASTHMACAP II). Med Clin (Barc) 2014; 142: 348-354

8 Côté J, Bowie DM, Robichaud P, et al. Evaluation of two different educational interventions for adult patients consulting with an acute asthma exacerbation. Am J Respir Crit Care Med 2014; 163: 1415-1419.

9 Charlton I, Charlton G, Broomfield J, et al. Evaluation of peak flow and symptoms only self management plans for control of asthma in general practice. BMJ 1990; 301: 1355-1359.

10 Gibson PG, Powell H. Written action plans for asthma: an evidence-based review of the key components. Thorax 2004; 59: 94-99.

11 López-Viña A, Del Castillo-Arévalo F. Influence of peak expiratory flow monitoring on asthma self-management education programme. Respir Med 2000; 94: 760-766.

12 GINA. Global Strategy for Asthma Management and Prevention. 2014. http://www.ginasthma.org/documents/4. Date last accessed: March 21, 2015.

13 Nathan RA, Sorkness CA, Kosinski M, et al. Development of the asthma control test: a survey for assessing asthma control. J Allergy Clin Immunol 2004; 113: 59-65.

14 Plaza V, ed. Guía de asma para pacientes. GEMA Pacientes [Guide for asthma patients. GEMA patients]. Madrid, Luzan 5, 2011.

15 Executive Committee GEMA 2009. GEMA 2009 (Spanish guideline on the management of asthma). J Investig Allergol Clin Immunol 2010; 20: Suppl. 1, 1-59.

16 Plaza V, ed. Manual del educador en asma. GEMA Educadores [Asthma educator's manual. GEMA Educators]. Madrid, Luzan 5, 2010

17 Vega JM, Badia X, Badiola C, et al. Validation of the Spanish version of the Asthma Control Test (ACT). J Asthma 2007; 44: 867-872.

18 Charlson ME, Pompei P, Ales KL, et al. A new method of classifying prognostic comorbidity in longitudinal studies: development and validation. J Chronic Dis 1987; 40: 373-383.

19 Juniper EF, Guyatt GH, Cox FM, et al. Development and validation of the Mini Asthma Quality of Life Questionnaire. Eur Respir J 1999; 14: 32-38.

20 Sanjuàs C, Alonso J, Sanchís J, et al. The quality-of-life questionnaire with asthma patients: the Spanish version of the Asthma Quality of Life Questionnaire. Arch Bronconeumol 1995; 31: 219-226.

21 Miller MR, Hankinson J, Brusasco V, et al. Standardisation of spirometry. Eur Respir J 2005; 26: 319-338.

22 Roca J, Sanchis J, Agusti-Vidal A, et al. Spirometric reference values from a Mediterranean population. Bull Eur Physiopathol Respir 1986; 22: 217-224.

23 Akaike H. A new look at the statistical model identification. IEEE Trans Automat Contr 1974; 19: 716-723.

24 Juniper EF, Guyatt GH, Willan A, et al. Determining a minimal important change in a disease-specific Quality of Life Questionnaire. J Clin Epidemiol 1994; 47: 81-87.

25 BTS. British guideline on the management of asthma. Thorax 2014; 69: Suppl. 1, i1-i192.

26 Caballero Martinez F, Plaza V, Quirce Gancedo S, et al. External assessment of the GEMA2009 recommendations by a multidisciplinary expert panel on asthma. Arch Bronconeumol 2010; 46: 411-419.

27 Plaza V, Bellido-Casado J, Alonso-Coello P, et al. Asthma clinical practice guidelines: advantages and pitfalls. Arch Bronconeumol 2009; 45: Suppl. 1, 25-29.

28 Prieto L, Badiola C, Villa JR, et al. Asthma control: do patients' and physicians' opinions fit in with patients' asthma control status? J Asthma 2007; 44: 461-467.

29 Demoly P, Paggiaro P, Plaza V, et al. Prevalence of asthma control among adults in France, Germany, Italy, Spain and the UK. Eur Respir Rev 2009; 18: 105-112.

30 Royal College of Physicians. Why asthma still kills: the National Review of Asthma Deaths (NRAD) Confidential Enquiry report. London, Royal College of Physicians, 2014. www.rcplondon.ac.uk/sites/default/files/why-asthmastill-kills-full-report.pdf. Date last accessed: March 21, 2015.

31 Haahtela T, Klaukka T, Koskela $\mathrm{K}$, et al. Asthma programme in Finland: a community problem needs community solutions. Thorax 2001; 56: 806-814.

32 Levy ML, Winter R. Asthma deaths: what now? Thorax 2015; 70: 209-210.

33 Pinnock H, Østrem A, Rodriguez MR, et al. Prioritising the respiratory research needs of primary care: the International Primary Care Respiratory Group (IPCRG) e-Delphi exercise. Prim Care Respir J 2012; 21: 19-27.

34 Tousman S, Zeitz H. A model for changing human health behavior: application to asthma management. Adv Psychosom Med 2003; 24: 86-97. 
35 Caress AL, Beaver K, Luker K, et al. Involvement in treatment decisions: what do adults with asthma want and what do they get? Results of a cross sectional survey. Thorax 2005; 60: 199-205.

36 Dunbar J, Marshall G, Hovell M. Behavioral strategies for improving compliance. In: Hayes RB, Taylor DW, Sackett DL, eds. Compliance in health care. Baltimore, Johns Hopkins University Press, 1979; pp. 174-190.

37 Evans D. To help patients control asthma the clinician must be a good listener and teacher. Thorax 1993; 48: 685-687.

38 Partridge MR, Hill SR. Enhancing care for people with asthma: the role of communication, education, training and self-management. 1998 World Asthma Meeting Education and Delivery of Care Working Group. Eur Respir J 2000; 16: 333-348

39 Ryan D, Murphy A, Ställberg B, et al. 'SIMPLES': a structured primary care approach to adults with difficult asthma. Prim Care Respir J 2013; 22: 365-373. 